\title{
REGULATION OF THIAMINE BIOSYNTHESIS UPON EXOGENOUS APPLICATION OF THE VITAMIN IN OIL PALM (Elaeis guineensis)
}

\section{ATIQAH SUBKI*; SITI FARIEDDA KHAIRI THAW* and ZETTY NORHANA BALIA YUSOF*}

\begin{abstract}
Thiamine (vitamin $B_{1}$ ) is an essential microelement that is synthesised de novo by plants and microorganisms. The active form of thiamine is thiamine pyrophosphate (TPP), which plays a prominent role in plant's metabolic activity particularly as an enzymatic cofactor. In vivo analysis of thiamine in oil palm was performed where four months old oil palm seedlings were treated with $125 \mathrm{ml}$ of $50 \mathrm{mM}$ thiamine hydrochloride and tissue samples were collected at Day 0,1,2 and 3. The expression of ThiC gene fragment was analysed via quantitative real time polymerase chain reaction ( $q P C R$ ) which showed an approximately five-fold decrease post-thiamine treatment. Analysis of thiamine and its derivatives via high performance liquid chromatography (HPLC) showed that the concentration of thiamine decreased, while TPP increased post-thiamine treatment. It is suggested that thiamine biosynthesis in oil palm can be effectively regulated at the physiological concentrations of the vitamin.
\end{abstract}

Keywords: thiamine, vitamin $\mathrm{B}_{1}$, ThiC gene, gene expression, oil palm.

Date received: 23 November 2017; Sent for revision: 31 December 2017; Received in final form: 23 March 2018; Accepted: 2 May 2018.

\section{INTRODUCTION}

Thiamine was the first B vitamin identified (Funk, 1975). Free thiamine, thiamine monophosphate (TMP) and thiamine pyrophosphate (TPP) are the three most dominant forms of the vitamin that exist in cells (Bettendorff et al., 2007). Vitamin $B_{1}$ is a watersoluble vitamin made by plants and microorganisms and it is an essential micronutrient in the human diet as humans are not able to synthesise vitamin $\mathrm{B}_{1}$ (Pourcel et al., 2013). TPP is a crucial co-factor in many enzymes involved in central metabolism such as acetyl-CoA biosynthesis, amino acid biosyntheis, Krebs cycle and Calvin cycle (Goyer, 2010).

Besides its role as a co-factor, thiamine has been reported to be possessing another crucial role

\footnotetext{
Department of Biochemistry, Faculty of Biotechnology and Biomolecular Sciences, Universiti Putra Malaysia, 43400 UPM Serdang, Selangor, Malaysia.

E-mail: zettynorhana@upm.edu.my
}

which is in plant protection against stress. Recent data suggests that boosting thiamine content could increase plants' resistance towards stresses (Ahn et al., 2007; Tunc-Ozdemir et al., 2009; Dong et al., 2016). In fact, comprehensive studies on the effect of biotic and abiotic stresses on the expression of thiamine biosynthesis genes in oil palm (Elaeis guineensis) have been reported (Balia Yusof et al., 2015; Wong et al., 2016; Zainal Abidin et al., 2016; Kamarudin et al., 2017). The study by Kamarudin et al. (2017) described the application of an endopytic fungus, Hendersonia toruloidea managed to elevate the expression of thiamine biosynthesis genes in oil palm and increased total thiamine accumulation in the plant. On the other hand, systemic acquired resistance (SAR) in Oryza sativa, Arabidopsis thaliana, Nicotiana sp. and Cucumis sativus were shown to be induced when thiamine was applied to these plants which portrayed the role of thiamine as a stress-responsive molecule in plants (Goyer, 2010). Besides that, thiamine was also shown to boost the immunity of potato plant (Vinchesi et al., 2017). 
A study by Croft et al. (2007) revealed the declination of ThiC gene expression upon exogenous application of thiamine in a green alga, Chlamydomonas reinhardti which suggests a feedback regulation system in thiamine biosynthesis. Additionally, a study proved that the relative gene expression of thiamine biosynthesis genes in a prasinophyte alga, Emiliania huxleyi was significantly increased when thiamine supply was exhausted (McRose et al., 2014). The same pattern was also demonstrated in cassava plant and the application of exogenous thiamine to the plant led to the formation of splicing variants of ThiC gene suggesting the presence of TPP riboswitch (Mangel et al., 2017).

Figure 1 illustrates the thiamine biosynthesis pathway in plants. Thiamine is composed of a thiazole ring linked to a pyrimidine ring by a methylene bridge (Dong et al., 2016). In plants, thiamine biosynthesis occurs in the chloroplast of plants through the separate formation of the pyrimidine and thiazole moieties, which are then coupled to form TMP. Phosphorylation of thiamine to TPP occurs in the cytosol. Therefore, thiamine (or TMP) must be exported from the chloroplast to the cytosol for the latter step to be accomplished. THIC or hydroxymethyl pyrophosphate (HMP-P) synthase is the first enzyme in pyrimidine branch in the thiamine biosynthesis pathway regulated by ThiC gene.

There is lack of understanding and knowledge on the effect of exogenous thiamine in oil palm that can be related to the presence of riboswitch. Thus, this study will generally gives an idea on how the application of exogenous thiamine will affect the expression of thiamine biosynthesis gene, specifically ThiC gene, coding for hydroxymethylpyrimidine, one of the first two enzymes in the branched thiamine biosynthesis pathway. This enzyme is responsible for the conversion of aminoimidazole ribonucleotide (AIR) to hydroxymethylpyrimidine phosphate (HMP-P), an important enzyme in the initial step of the pathway.

\section{MATERIALS AND METHODS}

\section{Oil Palm Sample}

Four months old oil palm seedlings were obtained from Malaysian Palm Oil Board (MPOB), Bangi, Selangor, Malaysia. All seedlings were acclimatised for one week for adaptation in Plant and Algae Biotechnology and Biochemistry Laboratory under constant condition. Oil palm seedlings were watered with $125 \mathrm{ml}$ of distilled water constantly at $4.00 \mathrm{pm}$ every day until the day of thiamine application.

\section{Application of Thiamine to Oil Palm Seedlings}

Thiamine-hydrochloride (Millipore, USA) with concentration of $50 \mathrm{mM}$ was prepared. Treatment was done using drenching technique by applying $125 \mathrm{ml}$ of thiamine-hydrochloride solution to the seedling. Samplings were done on Day 0, 1, 2 and 3 post-treatment. The spear leaves of the oil palm were cut, cleaned and immediately frozen in liquid nitrogen before being stored in $-80^{\circ} \mathrm{C}$ until further use.

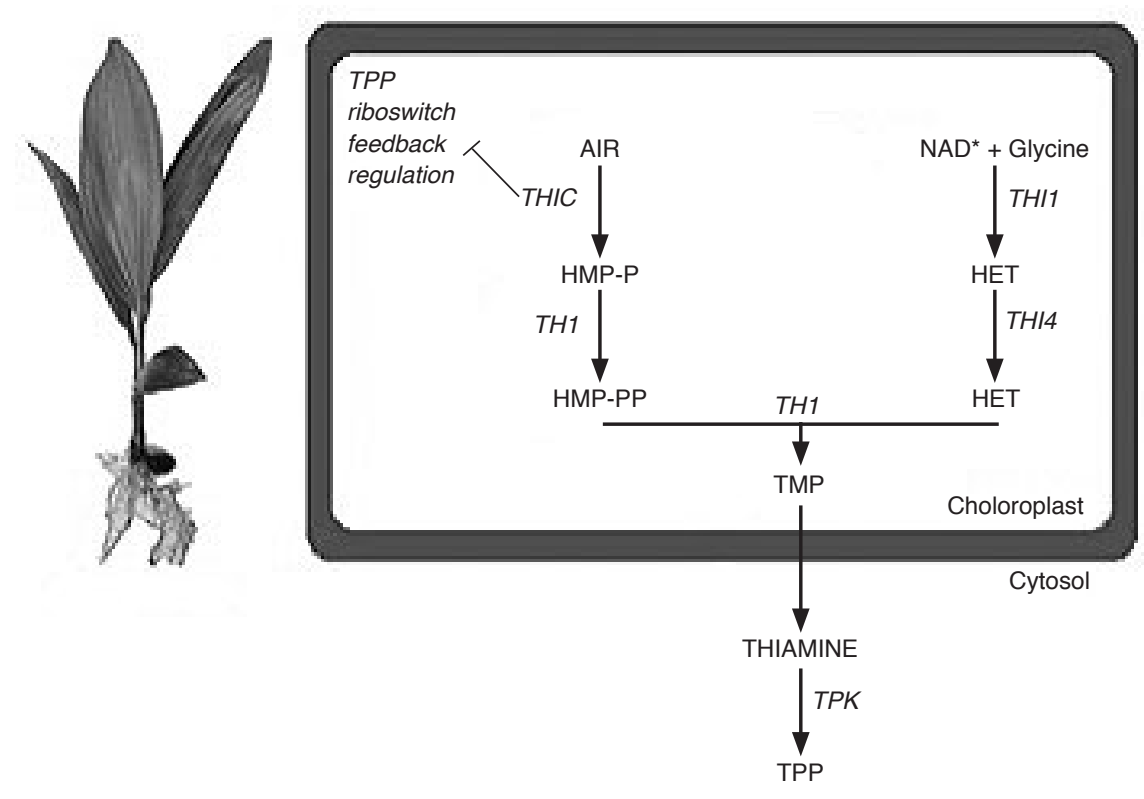

Figure 1. Thiamine biosynthesis pathway in plants comprises pyrimidine moiety and thiazole moiety being condensed together to form thiamine monophosphate (TMP). Subsequently, TMP is converted to thiamine and finally, thiamine pyrophosphate (TPP), which is an active derivative in many metabolic activities. 
RNA Isolation and Amplification of ThiC Gene Using Polymerase Chain Reaction (PCR)

The total RNA was extracted using Li and Trick method with modification (Li and Trick, 2005). DNase treatment was carried out according to Novagen DNase I, RNase-free Protocol (Novogen, USA). Reverse transcription was performed using Tetro cDNA Synthesis Kit (Bioline, USA). Specific primers were designed using Primer Premier 6.0 (Primer Biosoft,Palo Alto, USA). PCR was performed by using MyTaq ${ }^{\mathrm{TM}}$ Red Mix (Bioline, USA).

\section{Analysis of Gene Expression Using Quantitative Polymerase Chain Reaction (qPCR)}

The qPCR was done by using SensiFAST ${ }^{\mathrm{TM}}$ SYBR No-ROX Kit (Bioline, USA). Each reaction was done in triplicates and the expression of the gene of interest was analyzed against actin gene (Vandesompele et al., 2002). Upon normalisation, the expression of actin was indicated as zero giving the expression unit of thiamine biosynthesis gene, $\mathrm{ThiC}$ in relative quantity.

\section{DNA Cloning and Sequencing}

Purified PCR products were cloned into pGEMT vector (Promega, USA) and sequenced using $1^{\text {st }}$ Base Sequencing Service ( $1^{\text {st }}$ Base, Singapore). The result obtained was then analysed through Basic Local Alignment tools (BLAST) (http://blast.ncbi.nlm. nih.gov) for verification.

Quantification of Thiamine and its Metabolite using High Performance Liquid Chromatography (HPLC)

Determination of thiamine metabolites through HPLC was done to quantify the concentration of TMP, thiamine pyrophosphate (TPP) and THCl upon the application of exogenous thiamine. Method used was derived from Kamarudin et al. (2017). Vitamin $\mathrm{B}_{1}$ and its derivatives were extracted from $2.5 \mathrm{~g}$ spear leaves of oil palm sample in hydrochloric acid $(0.1 \mathrm{~N})$. The mixture was vortexed and incubated at $37^{\circ} \mathrm{C}$ overnight. The supernatant was then collected and further derivatisation of the extract using potassium ferricyanide and sodium hydroxide was carried out to oxidise the metabolite to its fluorescent derivative, thiochrome. The calibration curves of targeted metabolites (T-HCl, TMP, and TPP) were plotted through standard preparation at $10 \mathrm{ppm}, 2 \mathrm{ppm}, 1 \mathrm{ppm} 0.4 \mathrm{ppm}$ and $0.2 \mathrm{ppm}$. Quantification of thiamine vitamers were performed by integrating the corresponding fluorescent peak area extrapolated from standard curves. Data were normalised to tissue fresh weight.

\section{RESULTS AND DISCUSSION}

\section{Effect on ThiC Gene Expression upon Exogenous Thiamine Application}

RNA of oil palm seedlings was extracted on Day 0, 1, 2 and 3 post- treatment represented by D0, D1, D2 and D3, respectively. Plant roots can directly absorb thiamine when exogenous thiamine is applied. A study by Bonner suggested that exogenous free thiamine can penetrate plant leaves tissues and it can be transported throughout the plants through xylem and phloem in acro-petal and basi-petal directions (Bonner, 1942). The expression of ThiC gene upon application of exogenous thiamine was investigated via qPCR. All primers (Table 1) were designed by using software Primer Premier 6.0 (Primer Biosoft, Palo Alto, CA, USA). The primers were optimised to attain an optimal annealing temperature of $55^{\circ} \mathrm{C}$.

Figure 2 shows the relative quantity of $\mathrm{ThiC}$ gene expression in oil palm seedlings throughout the four days treatment. The decrease might be due to the presence of riboswitch in the ThiC gene as the exogenous thiamine applied have led to the excess formation of TPP which in turn will bind to the TPP riboswitch that eventually will downregulate the expression of ThiC gene. A similar analysis was done in Arabidopsis thaliana where the expression of ThiC gene was downregulated one day after 100 mg litre ${ }^{-1}$ of exogenous thiamine treatment and the expression intensity maintained at low level at six days post treatment (Kong et al., 2008).

A study on effect of exogenous thiamine on Chlamydomonas reinhardtii was done by supplying the microalgae cultures with $10 \mu \mathrm{M}$ of thiamine for $6 \mathrm{hr}$. After the addition of thiamine it was found that the ThiC gene transcript decreased consistently until 6 hr post-treatment (Croft et al., 2007). Previous

TABLE 1. LIST OF PRIMERS USED THROUGHOUT THE STUDY. ACTIN GENE WAS USED AS REFERENCE GENE WHILE ThiC GENE IS THE GENE POSTULATED TO CONTAIN TPP RIBOSWITCH

\begin{tabular}{llll}
\hline Gene & \multicolumn{1}{c}{ Type of primer } & \multicolumn{1}{c}{ Sequence } & Amplicon size (bp) \\
\hline Actin & Forward primer $\left(5^{\prime}-3^{\prime}\right)$ & $5^{\prime}$-CTTGCTCCAAGCAGCATGA-3' & 169 \\
& Reverse primer $\left(5^{\prime}-3^{\prime}\right)$ & $5^{\prime}$-AGAAGCACTTCCGGTGCACG-3' & \\
ThiC & Forward primer $\left(5^{\prime}-3^{\prime}\right)$ & $5^{\prime}$-GGTGCTGCTTCGCTACATTCCT-3' & 188 \\
& Reverse primer $\left(5^{\prime}-3^{\prime}\right)$ & $5^{\prime}$-GCCTCAACCCATCGCCAATAGA-3' & \\
\hline
\end{tabular}




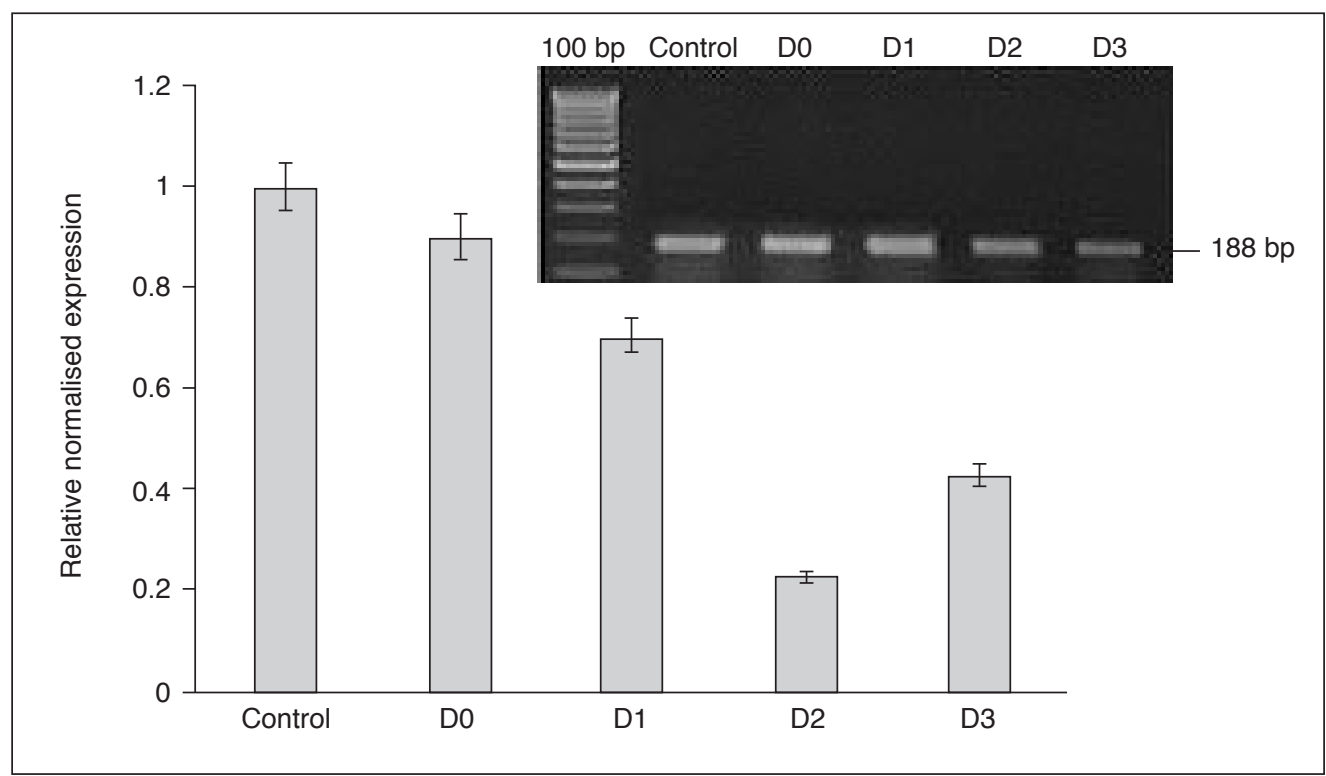

Note: Data presented are the mean \pm standard deviation of three replicates. Significant differences of $(\mathrm{P}<0.05)$ using Student's t-test.

Figure 2. Relative normalised expression of ThiC gene in thiamine treated oil palm seedlings analysis through quantitative real time polymerase chain reaction ( $q P C R)$ at Day 0, 1, 2 and 3 post-treatment.

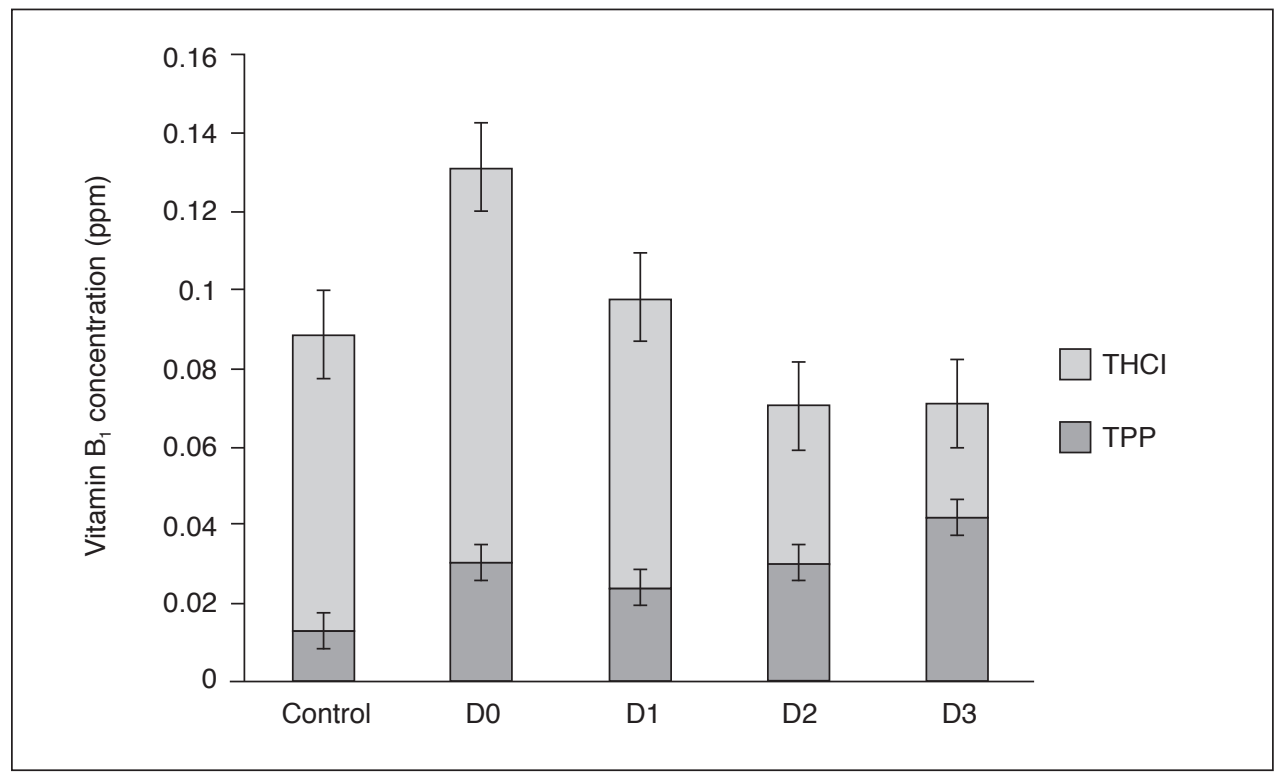

Note: Data presented are the mean \pm standard deviation of three replicates.

Figure 3. The two measured $B_{1}$ vitamers, thiamine hydrochloride (THCl) and thiamine pyrophosphate (TPP) in control (no thiamine) and thiamine treated oil palm seedlings at Day 0,1,2 and 3 post-treatment.

studies stated that TPP-binding riboswitches were responsible in controlling the thiamine biosynthesis in both $A$. thaliana and C. reinhardtii (Sudarsan et al., 2003). By comparing the ThiC gene expression of oil palm to both organisms, the prediction that that TPP-riboswitch may also be present in the ThiC gene of oil palm and involved in controlling thiamine biosynthesis pathway is highly supported.

\section{Quantification of Thiamine and its Metabolite Using HPLC}

Thiamine metabolites namely thiamine and TPP were measured through fluorescence detection instead of UV detection, as thiamine metabolites were unstable and sensitive to UV light which may cause degradation of metabolites during the analysis 
(Julliard and Douce, 1991). Calibration of standard was done and the retention times were at minutes 5.726, 6.689 and 8.550 for TPP, TMP (thiamine monophosphate) and thiamine, respectively.

Analysis of metabolites via HPLC showed the concentration of thiamine decreased postthiamine treatment while TPP metabolites increased post-thiamine treatment as shown in Figure 3. Nonetheless, there was no TMP metabolite detected from the extract. The down regulation of $\mathrm{ThiC}$ gene expression could be related to the absence of TMP metabolites. When exogenous thiamine was applied to oil palm seedlings, the metabolites were absorbed and entered thiamine biosynthesis pathway that increased the concentration of thiamine in the plant. The decline in thiamine and increase in TPP metabolites could actually be related to the phosphorylation of thiamine into $\mathrm{TPP}$, which is the active form of thiamine. The presence of excess TPP led to the binding to the TPP riboswitch that eventually caused the down regulation of ThiC gene expression. Negative correlation between metabolite content and ThiC gene expression suggests the negative feedback regulation conducted by TPP riboswitch present in the ThiC gene as previously reported (Bocobza et al., 2013; Mangel et al., 2017).

\section{CONCLUSION}

It is suggested that thiamine biosynthesis in oil palm can be effectively regulated by the physiological concentrations of the vitamin. This knowledge could be applied for various purposes like disease control and stress management of oil palm. This study highlights the role of application of exogenous thiamine and feedback regulatory mechanism conducted by TPP riboswitch which is postulated to be present in the ThiC gene of oil palm.

\section{REFERENCES}

AHN, I P; KIM, S; LEE, Y H; SUH, S C and AL, E (2007). Vitamin B1-induced priming is dependent on hydrogen peroxide and the NPR1 gene in Arabidopsis. Plant Physiology, 143: 838-848.

BALIA YUSOF, Z N; BORHAN, F P; MOHAMAD, F A and RUSLI, M H (2015). The effect of Ganoderma boninense infection on the expresions of thiamine (vitamin B1) biosynthesis genes in oil palm. J. Oil Palm Res. Vol. 27: 12-18.

BETTENDORFF, L; WIRTZFELD, B; MAKARCHIKOV, A F; MAZZUCCHELLI, G; FRÉDÉRICH, M; GIGLIOBIANCO, T; GANGOLF, M; DE PAUW, E; ANGENOT L and WINS, P (2007). Discovery of a natural thiamine adenine nucleotide. Nature Chemical Biology, 3: 211-212.
BOCOBZA, S E; MALITSKY, S; ARAÚJO, W L; NUNES-NESI, A; MEIR, S; SHAPIRA, M; FERNIE, A R and AHARONI, A (2013). Orchestration of thiamin biosynthesis and central metabolism by combined action of the thiamin pyrophosphate riboswitch and the circadian clock in Arabidopsis. The Plant Cell, 25: 288-307.

BONNER, J (1942). Transport of thiamin in the tomato plant. American J. Botany, 29: 136-142.

CROFT, M T; MOULIN, M; WEBB, $\mathrm{M}$ E and SMITH, A G (2007). Thiamine biosynthesis in algae is regulated by riboswitches. Proc. of the National Academy of Sciences of the USA, 104: 20770-5.

DONG, W; THOMAS, N; RONALD, PC and GOYER, A (2016). Overexpression of thiamin biosynthesis genes in rice increases leaf and unpolished grain thiamin content but not resistance to Xanthomonas oryzae pv. oryzae. Frontiers in Plant Science, 7: 616.

FUNK, C (1975). The etiology of the deficiency. Analytica Chimica Acta, 76: 176-177.

GOYER, A (2010). Thiamine in plants: Aspects of its metabolism and functions. Phytochemistry, 71: 16151624.

JULLIARD, J H and DOUCE, R (1991). Biosynthesis of the thiazole moiety of thiamin (vitamin B1) in higher plant chloroplasts. Proc. of the National Academy of Sciences, 88: 2042-2045.

KAMARUDIN, A N; SONG, L K; LAMASUDIN, D U; IDRIS, A S and BALIA YUSOF, Z N (2017). Enhancement of thiamine biosynthesis in oil palm seedlings by colonization of endophytic fungus Hendersonia toruloidea. Frontiers in Plant Science, 8: 1799.

KONG, D; ZHU, Y; WU, H; CHENG, X; LIANG, H and LING, H Q (2008). AtTHIC, a gene involved in thiamine biosynthesis in Arabidopsis thaliana. Cell Research, 18: 566-576.

LI, Z and TRICK, H N (2005). Rapid method for high-quality RNA isolation from seed endosperm containing high levels of starch. BioTechniques, 38: $872-876$

MANGEL, N; FUDGE, J B; FITZPATRICK, T B; GRUISSEM, $\mathrm{W}$ and VANDERSCHUREN, $\mathrm{H}$ (2017). Vitamin B1 diversity and characterization of biosynthesis genes in cassava. J. Experimental Botany, 42: 322-327.

MCROSE, D; GUO, J; MONIER, A; SUDEK, S; WILKEN, S; YAN, S; MOCK, T; ARCHIBALD, J M; 
BEGLEY, T P; REYES-PRIETO, A and WORDEN, A $Z$ (2014). Alternatives to vitamin B1 uptake revealed with discovery of riboswitches in multiple marine eukaryotic lineages. The ISME J., 8: 2517-2529.

POURCEL, L; MOULIN, M; FITZPATRICK, T B and AL, E (2013). Examining strategies to facilitate vitamin B1 biofortification of plants by genetic engineering. Frontiers in Plant Science, 4: 160.

SUDARSAN, N; WICKISER, J K; NAKAMURA, S; EBERT, M S and BREAKER, R R (2003). An mRNA structure in bacteria that controls gene expression by binding lysine. Genes and Development, 17: 26882697.

TUNC-OZDEMIR, M; MILLER, G; SONG, L; KIM, J; SODEK, A; KOUSSEVITZKY, S; MISRA, A N; MITTLER, R and SHINTANI, D (2009). Thiamin confers enhanced tolerance to oxidative stress in Arabidopsis. Plant Physiology, 151: 421-432.

VANDESOMPELE, J; DE PRETER, K; PATTYN, I; POPPE, B; VAN ROY, N; DE PAEPE, A and
SPELEMAN, R (2002). Accurate normalization of real-time quantitative RT-PCR data by geometric averaging of multiple internal control genes. Genome Biology, 3: 34-41.

VINCHESI, A C; RONDON, S I and GOYER, A (2017). Priming potato with thiamin to control potato virus Y. American J. Potato Research, 94: 120128.

WONG, S Y; SYAMIMI, D A A and BALIA YUSOF, ZN (2016). Osmotic stress upregulates the transcription of thiamine (vitamin B1) biosynthesis genes (THIC and THI4) in oil palm (Elaies guineensis). African J. Biotechnology, 15: 1566-1574.

ZAINAL ABIDIN, A A; YEE, W S; ABDUL RAHMAN, N S; CHE IDRIS, $\mathrm{Z} \mathrm{H}$ and BALIA YUSOF, Z N (2016). Osmotic, oxidative and salinity stresses upregulate the expressions of thiamine (vitamin B1) biosynthesis genes (THIC and THI1/ THI4) in oil palm (Elaeis guineensis). J. Oil Palm Res. Vol. 28: 308-319. 